\title{
RESPOSTA DE MUDAS DE GOIABEIRA A DOSES E MODOS DE APLICAÇÃO DE FERTILIZANTE FOSFATADO ${ }^{1}$
}

\author{
MÁRCIO CLEBER DE MEDEIROS CORRÊA², RENATO DE MELLO PRADO², WILLIAM NATALE ${ }^{3}$, LUCIANO \\ PEREIRA $^{4}$, JOSÉ CARLOS BARBOSA ${ }^{5}$
}

\begin{abstract}
RESUMO - O presente trabalho objetivou avaliar o desenvolvimento de mudas de goiabeira em resposta a doses e modos de aplicação de fertilizante fosfatado. As mudas de goiabeira foram transplantadas em conjuntos de vasos (sacos plásticos, 18 x $28 \mathrm{~cm}$ ) geminados, contendo em cada lado 2,8 $\mathrm{dm}^{3}$ do subsolo de um Argissolo (P resina $=1 \mathrm{mg} \mathrm{dm}^{-3}$ ), de modo que a metade do sistema radicular ficasse em cada vaso. Usou-se um fatorial $2 \times 3 \mathrm{x}$

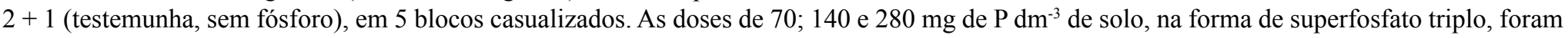
aplicadas de dois modos diferentes com relação ao solo (distribuído em todo o volume do solo ou localizado a 1/3 de profundidade) e dois modos diferentes com relação às raízes (dividindo-se a dose igualmente entre os dois vasos do conjunto ou aplicando-se a dose total em um único vaso). Cem dias após o transplante, verificou-se maior acúmulo de $\mathrm{P}$ e maior produção de matéria seca nas plantas que receberam adubação fosfatada. As mudas de goiabeira responderam positivamente à adubação fosfatada, sendo a dose próxima de $100 \mathrm{mg} \mathrm{de} \mathrm{P} \mathrm{dm}{ }^{-3}$ de solo suficiente para o bom desenvolvimento das plantas. Doses acima de $200 \mathrm{mg}$ de $\mathrm{P} \mathrm{dm}^{-3}$ promoveram redução do crescimento das mudas de goiabeira. A disponibilização de fósforo à metade ou a todo o sistema radicular da goiabeira não afetou o suprimento desse nutriente às mudas e tampouco o seu desenvolvimento. A aplicação do adubo fosfatado distribuído em todo o volume de solo no vaso proporcionou maior desenvolvimento do sistema radicular e menor desenvolvimento da parte aérea das mudas de goiabeira, comparado à aplicação localizada do adubo a 1/3 de profundidade.
\end{abstract}

Termos para indexação: Psidium guajava, goiaba, frutífera, localização de P, raízes subdivididas.

\section{RESPONSE OF GUAVA TO RATES AND PLACEMENT OF PHOSPHATE FERTILIZER}

\begin{abstract}
The objective of the present study was to assess the development of guava tree cuttings in response to different doses and modes of application of phosphate fertilizer. The guava tree cuttings were transplanted in twin sets of pots ( $18 \times 28 \mathrm{~cm}$ plastic bags $)$ containing $2.8 \mathrm{dm}^{3}$ of the subsoil of a Argisol (Ultisol, Soil Taxonomy; P resin = $1 \mathrm{mg} \mathrm{dm}^{-3}$ ) in such a way that half of the root system would remain in each pot. A $2 \times 3 \times 2+1$ factorial arrangement (check, without phosphate) in 5 randomized blocks was used. Doses of 70, 140 and $280 \mathrm{mg}$ of Pdm ${ }^{-3}$ of soil in form of triple superphosphate were applied in two different manners to the soil (distributed throughout the soil volume or placed only at a depth of $1 / 3$ ) and in the roots (by dividing the dose equally between the two pots of the set or by applying the total dose to a single pot). The greatest accumulation of $\mathrm{P}$ and the greatest production of dry matter was observed 100 days after transplant in the plants that received phosphate fertilizer. The guava cuttings responded positively to phosphate fertilization, with the dose of about $100 \mathrm{mg} \mathrm{of} \mathrm{Pdm}^{-3}$ of soil being sufficient for good plant development. Doses above of 200 $\mathrm{mg} \mathrm{Pdm}{ }^{-3}$ promoted a reduction of plant growth. Making phosphorus available to half or to the entire root system of the guava plant did not affect the supply of this nutrient to the cuttings or their development. The application of phosphate fertilizer distributed throughout the soil volume in the pot favored a better development of the root system and a lower development of the aerial part of the guava cuttings compared to application of the fertilizer localized at a depth of $1 / 3$.
\end{abstract}

Index terms: Psidium guajava, cuttings, fruit tree, phosphorus placement, split-root.

\section{INTRODUÇÃO}

Originária da América tropical, a goiabeira (Psidium guajava L., família: Myrtaceae) apresenta grande importância socioeconômica para o Brasil, que figura entre os três maiores produtores de goiaba do mundo, juntamente com a Índia e o Paquistão.

No Brasil, há pomares distribuídos por todas as regiões do País, os quais, juntos, totalizaram uma produção de 240 mil $\mathrm{t}$ da fruta fresca em 1999, numa área colhida de 12,6 mil ha (Agrianual, 2002). No Estado de São Paulo, responsável por quase $70 \%$ da produção nacional nos últimos anos (Agrianual, 2002), em 2000, contabilizava-se ao redor de 630.000 e 802.000 árvores em produção para mesa e para indústria, respectivamente, e 124.000 e 131.000 novas plantas, respectivamente, na mesma ordem (Anuário..., 2001). Esses números demonstram uma sensível expansão e/ou renovação da cultura, cujo sucesso depende da formação de mudas vigorosas, potencialmente produtivas e com frutos de boa qualidade.

As mudas de goiabeira têm sido desenvolvidas, preferencialmente, de forma vegetativa (estaquia), utilizando-se de cultivares melhoradas, altamente produtivas e exigentes em termos nutricionais (Natale et al., 1996; Natale et al., 2000), o que demanda a adoção de técnicas apropriadas, desde a fase de formação das mudas.
Nesse contexto, o substrato utilizado para o desenvolvimento radicular e suporte da planta, durante a formação das mudas, interfere no sucesso dessa etapa e das seguintes, após o estabelecimento do pomar no campo. Para tanto, tem-se utilizado o subsolo como substrato para o desenvolvimento inicial das plantas (Picheth, 1987) que, embora apresentem, baixa fertilidade, têm a vantagem de reduzir os riscos de introdução de plantas invasoras e patógenos, bem como a redução da expansão de áreas degradadas pela extração de solo.

Os solos e subsolos das regiões tropicais apresentam, normalmente, pequena disponibilidade de fósforo às plantas e elevado poder de adsorção/fixação deste nutriente (Novais \& Smyth, 1999). Por outro lado, este é um elemento indispensável para o completo ciclo das plantas, influenciando de modo particular o crescimento de raízes (Marschner, 1995). Além disso, as exigências das plantas quanto ao P são maiores no período inicial de seu desenvolvimento (Novais et al., 1982; Römer \& Schilling, 1986); o satisfatório suprimento de P nessa fase é decisivo para a formação de mudas vigorosas (Natale et al., 2000) e, conseqüentemente, para o rápido estabelecimento de pomares de frutíferas perenes, como a goiabeira. Há registros na literatura da necessidade de doses desde 100 até $280 \mathrm{mg}$ de $\mathrm{P} \mathrm{dm}{ }^{-3}$ de solo para a boa formação de mudas de goiabeira (Natale et al., 2000; Salvador et al., 2000).

\footnotetext{
${ }^{1}$ (Trabalho 096/2002). Recebido: 04/07/2002. Aceito para publicação: 05/03/2003.

${ }^{2}$ Doutorando, Departamento de Solos e Adubos, FCAV/Unesp, campus Jaboticabal. E-mail: mcleber@fcav.unesp.br. Bolsista da FAPESP.

${ }^{3}$ Professor Adjunto, Departamento de Solos e Adubos, FCAV/Unesp, campus Jaboticabal. Via de Acesso Prof. Paulo Donato Castellane, s/n., 14870000, Jaboticabal - SP, Brasil. E-mail: natale@fcav.unesp.br. Bolsista do CNPq.

${ }^{4}$ Graduando em Agronomia, FCAV/Unesp, campus Jaboticabal.

${ }^{5}$ Professor Titular, Departamento de Ciências Exatas, FCAV/Unesp, campus Jaboticabal.
} 
A imobilidade do P no solo, devido ao elevado poder de adsorção/fixação em solos brasileiros, torna premente estudos sobre o modo de aplicação do fertilizante, buscando-se atender às exigências da planta, sem esquecer o aspecto operacional e econômico.

A aplicação localizada do adubo fosfatado restringe o acesso das raízes das plantas, ou seja, apenas parte do sistema radicular entrará em contato com o fertilizante, absorvendo-o efetivamente (Novais \& Smyth, 1999). Portanto, embora a aplicação de fósforo em volumes restritos de solo reduza sua adsorção e precipitação, tornando-o mais disponível às plantas (Anghinoni, 1992; Model \& Anghinoni, 1992; Prado et al., 2001), a aplicação localizada do P não acarretará, necessariamente, num suprimento satisfatório desse nutriente às mesmas; tal comportamento estará relacionado à planta em questão.

Estudos têm mostrado diferenças de resposta entre espécies vegetais quanto à localização do $\mathrm{P}$ em relação ao sistema radicular. Para soja, a absorção de fósforo e a produção das plantas independem da quantidade de raízes em contato com o adubo, desde que o mesmo seja fornecido em doses adequadas (Machado et al., 1983a, b; Dedecek et al., 1986); no caso do milho, para alguns autores, o adequado suprimento de $\mathrm{P}$, crescimento das plantas e produção dependem do máximo volume de raízes em contato com o P (Anghinoni \& Barber, 1980; Novais et al., 1985; Klepker e Anghinoni, 1995), embora Silva et al. (1993) tenham verificado crescimento do milho independentemente do método de localização do fosfato solúvel.

Para a goiabeira, o fósforo tem sido aplicado, preferencialmente, em todo o volume disponível de solo, quando se trata da produção de mudas e, no campo, de forma localizada, na cova de plantio e/ou na superfície do solo sob pomares instalados. Todavia, são quase inexistentes pesquisas acerca desse procedimento. Assim, no presente trabalho, avaliou-se o desenvolvimento de mudas de goiabeira, em resposta a doses e modos de aplicação de fertilizante fosfatado.

\section{MATERIAL E MÉTODOS}

O experimento foi desenvolvido em um viveiro comercial de mudas, localizado na Rodovia Washington Luiz, km 333,8 no município de Taquaritinga - SP $\left(21^{\circ} 24^{\prime}\right.$ de latitude Sul, $48^{\circ} 29^{\prime}$ de longitude Oeste e altitude de $521 \mathrm{~m}$ ), entre outubro de 2000 e março de 2001.

Foi utilizado um substrato constituído de um Argissolo Vermelho-Amarelo, coletado em área do próprio viveiro, na profundidade de 0,3 a 4,0 $\mathrm{m}$. A análise química do solo revelou as seguintes propriedades: $\mathrm{pH} \mathrm{CaCl}_{2}=4,3 ;$ M.O. $=6 \mathrm{~g} \mathrm{dm}^{-3} ; \mathrm{P}$ resina $=1 \mathrm{mg} \mathrm{dm}{ }^{-3} ; \mathrm{K}=0,7 ; \mathrm{Ca}=6 ; \mathrm{Mg}$ $=3 ; \mathrm{H}+\mathrm{Al}=25 \mathrm{mmol}_{\mathrm{cm}} \mathrm{dm}^{-3} ; \mathrm{V}=28 \%$. Além disso, o Argissolo usado apresentou 260; 458; 25 e $157 \mathrm{~g} \mathrm{~kg}^{-1}$ de areia grossa, areia fina, silte e argila, respectivamente.

Sessenta e oito dias antes da instalação do experimento, realizou-se a calagem do solo (substrato) com um calcário calcinado, objetivando-se atingir 70\% de saturação por bases, considerada ideal para a cultura (Santos \& Quaggio, 1996).

Mudas, com aproximadamente 180 dias de idade, obtidas de estacas herbáceas de matrizes de goiabeiras (Psidium guajava L.) cv. Paluma, foram retiradas dos recipientes plásticos e tiveram suas raízes aparadas e a parte aérea podada, a cerca de $15-20 \mathrm{~cm}$ de comprimento, a fim de torná-las o mais uniforme possível quanto à massa vegetal. Em seguida, foram transplantadas em "vasos" (sacos plásticos pretos com dimensão de 18 × $28 \mathrm{~cm}$ ) geminados, contendo em cada lado $2,8 \mathrm{dm}^{3} \mathrm{de}$ substrato, de modo que a metade do sistema radicular ficasse em cada vaso. Adaptado de Machado et al. (1983b) e Novais et al. (1985).

Adotou-se um delineamento experimental em blocos casualizados, com 5 repetições, em esquema fatorial $2 \times 3 \times 2$ (dois modos de aplicação do adubo fosfatado em relação ao solo $\mathrm{x}$ três doses de fósforo $\mathrm{x}$ dois modos de aplicação do adubo fosfatado em relação às raízes), mais um tratamento adicional (testemunha, sem fósforo), totalizando 65 parcelas compostas por uma planta e um conjunto de vasos (dois sacos plásticos geminados).

As doses de fósforo aplicadas em cada conjunto de vasos foram de $70 ; 140$ e $280 \mathrm{mg}$ de $\mathrm{P} \mathrm{dm} \mathrm{dm}^{-3}$ de solo, na forma de superfosfato triplo $\left(41 \%\right.$ de $\left.\mathrm{P}_{2} \mathrm{O}_{5}\right)$. A aplicação do adubo fosfatado foi realizada de dois modos diferentes com relação ao solo: distribuído em todo o volume de solo disponível ( $100 \%$ do volume de solo do vaso) e localizado a $1 / 3$ de profundidade ( $10 \%$ do volume de solo), e dois modos diferentes com relação às raízes: dividindo-se a dose igualmente entre os dois vasos do conjunto, ou aplicando-se a dose total em um único vaso.

Por ocasião do transplantio, cada parcela recebeu $75 \mathrm{mg}$ de

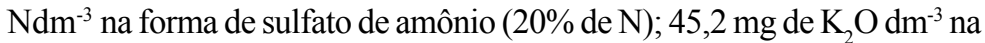
forma de cloreto de potássio $\left(60 \%\right.$ de $\left.\mathrm{K}_{2} \mathrm{O}\right) ; 5 \mathrm{mg}$ de $\mathrm{Zn} \mathrm{dm}{ }^{-3}$ na forma de sulfato de zinco ( $22 \%$ de $\mathrm{Zn}$ ) e $0,5 \mathrm{mg} \mathrm{de} \mathrm{B} \mathrm{dm} \mathrm{dm}^{-3}$ na forma de ácido bórico ( $17 \%$ de B). Os fertilizantes foram misturados em todo o volume do substrato.

As plantas foram mantidas por 40 dias sob telado $(50 \%$ de sombreamento) e mais 60 dias a pleno sol. Aos 30; 45 e 60 dias após o transplantio, receberam adubação de cobertura, cada uma com $75 \mathrm{mg}$ de $\mathrm{N} \mathrm{dm}^{-3}$ na forma de uréia ( $45 \%$ de $\mathrm{N}$ ) e $60{\mathrm{mg} \mathrm{de} \mathrm{K}_{2} \mathrm{O} \mathrm{dm}}^{-3}$ (cloreto de potássio). Os tratos culturais (irrigação, controle de ervas invasoras, pragas e doenças), no período de condução do experimento, foram os normalmente utilizados pelo viveirista.

Cem dias após o transplante, quando as mudas estavam prontas para o plantio no campo, foram coletados plantas e solo para análises em laboratório. As mudas tiveram a parte aérea cortada rente ao solo, e as raízes separadas do mesmo e lavadas em água corrente e água destilada. Na parte aérea e nas raízes, foram determinados a massa da matéria seca $\left(\sim 65^{\circ} \mathrm{C}\right)$, gravimetricamente, e o conteúdo de $\mathrm{P}$ (digestão nítrico-perclórica). Além disso, determinou-se o comprimento total de ramos, contou-se o número total de folhas e estimou-se a área foliar total por planta com auxílio de um aparelho integrador de áreas portátil LICOR modelo LI-3000A. No solo, foi determinada a concentração de P (Raij et al., 1987). De posse dos resultados, procedeu-se à análise de variância e à comparação de médias pelo teste de Tukey ou análise de regressão. Antes das análises estatísticas, os dados de número de folhas foram transformados em raiz quadrada, com a finalidade de obter-se uma distribuição normal.

\section{RESULTADOS E DISCUSSÃO}

Verificou-se que a adubação fosfatada induziu maior "disponibilidade" de fósforo no solo e, conseqüentemente, maior acúmulo de $\mathrm{P}$ nas plantas (raízes e parte aérea), refletindo positivamente na produção de massa seca (raízes e parte aérea), área foliar, número de folhas e comprimento total dos ramos das mudas de goiabeira, comparado à testemunha (dose zero de P).

\section{Efeito dos tratamentos no solo}

Como era esperado, a localização do fertilizante a $1 / 3$ de profundidade proporcionou maior concentração de "P-disponível" no solo, independentemente da dose, comparada à aplicação realizada em todo o volume de solo (Tabela 1). Analogamente, a aplicação em um vaso permitiu maior "disponibilização" do nutriente para as plantas do que em dois vasos. Isso se deve à menor adsorção do fósforo pelo solo nos tratamentos em que o contato adubo-solo foi mais restrito.

Com o incremento nas doses do fertilizante, o "P-disponível" no solo aumentou de forma linear nos tratamentos em que a aplicação foi feita em um só vaso e, de forma quadrática, quando aplicado nos dois vasos (Figura 1).

No caso em que o $P$ foi aplicado em um vaso, a taxa de crescimento do "P-disponível" no solo em função das doses de P aplicadas foi constante e igual a 0,162 (relação "P-disponível" no solo/dose de P aplicada; $\mathrm{y}=0,162 \mathrm{x}$ ). Com a aplicação de $\mathrm{P}$ em dois vasos, a taxa de "disponibilização" de fósforo é inicialmente baixa, variando de 0,011 (dose zero) a 0,095 (140 $\left.\mathrm{mg} \mathrm{dm}^{-3}\right)$, e atingindo o valor de 0,179 na maior dose testada $\left(280 \mathrm{mg} \mathrm{dm}^{-3}\right)$. Esse fato indica a possível saturação dos sítios de adsorção de $\mathrm{P}$, nas doses mais elevadas, independentemente da forma de aplicação, ou com a aplicação de doses mais baixas em volume de solo menor. 
TABELA 1- Efeito do modo de aplicação do fertilizante fosfatado, em relação ao solo (distribuído em todo o solo do vaso e localizado a $1 / 3$ de profundidade no vaso) e às raízes (em 2 vasos e em 1 vaso), na concentração de fósforo do solo e no desenvolvimento de mudas de goiabeira 'Paluma', aos 100 dias após o transplantio e a adubação fosfatada.

\begin{tabular}{|c|c|c|c|c|c|c|c|c|}
\hline \multirow{2}{*}{$\begin{array}{l}\text { Modo de Aplicação de } \\
\text { P em Relação ao Solo }\end{array}$} & \multirow[t]{2}{*}{ P do Solo } & \multirow[t]{2}{*}{ Área Foliar } & \multirow{2}{*}{$\begin{array}{l}\text { Número de } \\
\text { Folhas }\end{array}$} & \multirow[t]{2}{*}{ CTR* } & \multicolumn{2}{|c|}{ Matéria Seca } & \multicolumn{2}{|c|}{$P$ acumulado } \\
\hline & & & & & Raízes & Parte Aérea & Raízes & Parte Aérea \\
\hline & $\mathrm{mg} \mathrm{dm}^{-3}$ & $\mathrm{~cm}^{2}$ & & $\mathbf{c m}$ & \multicolumn{2}{|c|}{ g por planta } & \multicolumn{2}{|c|}{ mg por planta } \\
\hline $\begin{array}{l}\text { Distribud } \\
\text { Localizado } \\
\text { Modo de Aplicação de } \\
\text { P em Relação às Raízes }\end{array}$ & $\begin{array}{l}19,6 \mathrm{~B} \\
22,4 \mathrm{~A}\end{array}$ & $\begin{array}{l}1884 \\
1809\end{array}$ & $\begin{array}{l}51,5 \\
50,5\end{array}$ & $\begin{array}{l}127,1 \\
119,7\end{array}$ & $\begin{array}{l}5,25 \mathrm{~A} \\
4,93 \mathrm{~B}\end{array}$ & $\begin{array}{l}21,60 \mathrm{~B} \\
23,50 \mathrm{~A}\end{array}$ & $\begin{array}{l}5,20 \\
5,22\end{array}$ & $\begin{array}{l}29,95 \mathrm{~B} \\
33,21 \mathrm{~A}\end{array}$ \\
\hline $\begin{array}{l}2 \text { vasos } \\
1 \text { vaso }\end{array}$ & $\begin{array}{l}14,8 \mathrm{~B} \\
27,2 \mathrm{~A}\end{array}$ & $\begin{array}{l}1763 \\
1930\end{array}$ & $\begin{array}{l}49,2 \\
52,7\end{array}$ & $\begin{array}{l}119,5 \\
127,4\end{array}$ & $\begin{array}{l}5,15 \\
5,03\end{array}$ & $\begin{array}{l}22,41 \\
22,69\end{array}$ & $\begin{array}{l}5,53 \mathrm{~A} \\
4,90 \mathrm{~B}\end{array}$ & $\begin{array}{l}31,62 \\
31,54\end{array}$ \\
\hline
\end{tabular}

* CTR = comprimento total de ramos.

Médias seguidas da mesma letra, nas colunas, não diferem significativamente entre si, pelo teste de Tukey, a 5\% de probabilidade.

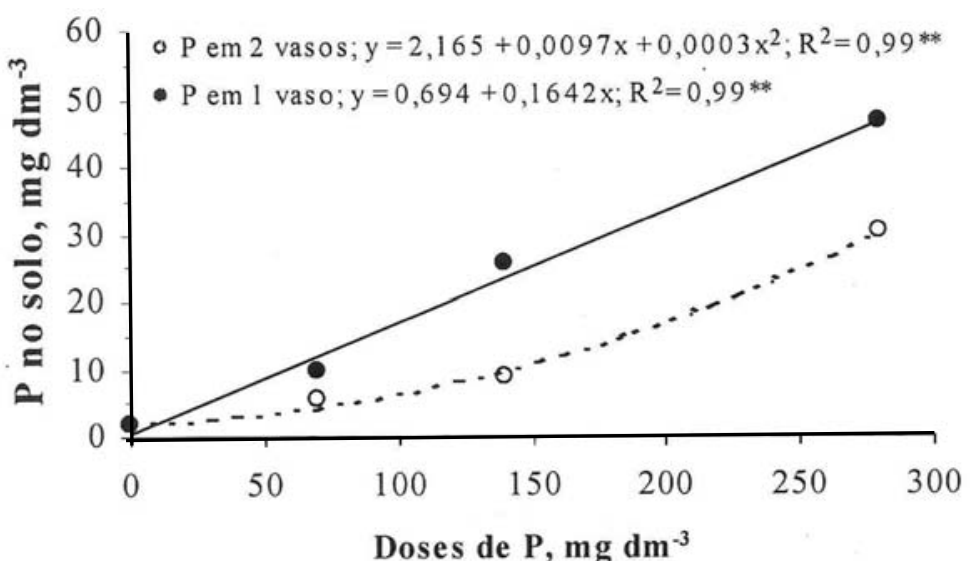

FIGURA 1- Efeito de doses de fósforo aplicadas em 2 vasos e em 1 vaso, na concentração de fósforo no solo.

\section{Efeito dos tratamentos sobre o acúmulo de $\mathrm{P}$ e desenvolvimento das mudas de goiabeira}

Na planta, a aplicação localizada do fertilizante a 1/3 de profundidade permitiu maior acúmulo de $\mathrm{P}$ e maior produção de matéria seca da parte aérea. Nas raízes, não houve efeito sobre o acúmulo de $\mathrm{P}$, e a produção de matéria seca sofreu efeito inverso ao observado na parte aérea, ou seja, a distribuição do adubo em todo o volume de solo proporcionou maior massa de raízes (Tabela 1). Dessa forma, pode-se inferir que a concentração de fósforo "disponível" no solo constituiu-se em fator limitante ao desenvolvimento da parte aérea das mudas nos tratamentos em que a fonte de fosfato solúvel foi distribuída em todo o volume de solo; por outro lado, favoreceu o crescimento de raízes. Resultados semelhantes foram observados por Machado et al. (1983b), em plantas de soja, e por Silva et al. (1993), em milho. O menor crescimento de raízes, causado pela localização do adu- bo no solo, é atribuído à ausência de $\mathrm{P}$ externo em boa parte do sistema de raízes, pois, segundo Robertson et al. (1966), a presença de "P-disponível" no solo é essencial para o aumento da força do dreno e da capacidade de utilização de fotoassimilados pelas regiões meristemáticas das raízes.

Assim, entende-se que o estímulo ao crescimento radicular, ocorrido numa região restrita do solo (correspondente aos $10 \%$ do volume total de solo onde $\mathrm{P}$ foi aplicado localizadamente), não foi suficiente para promover um crescimento de raízes equivalente ao obtido quando todo o sistema radicular foi estimulado (aplicação de P distribuída em 100\% do volume de solo disponível). Entretanto, o conteúdo de $\mathrm{P}$ e o crescimento da parte aérea indicam que, com a restrição do volume de raízes em contato com o adubo fosfatado, a fração do sistema radicular efetivamente ativa no processo de absorção de $\mathrm{P}$ passou a absorvê-lo em maior quantidade por unidade de raiz, compensando o restante das raízes privadas do contato com o nutriente. Esse fato é evidenciado pela elevação das constantes cinéticas de absorção do fósforo pelas raízes nas regiões do solo com maior concentração do elemento (Anghinoni \& Barber, 1980).

O modo de aplicação de fósforo com relação às raízes, em um vaso ( $50 \%$ do sistema radicular tem algum contato com o adubo fosfatado) ou nos dois vasos $(100 \%$ do sistema radicular tem algum contato com o adubo fosfatado) foi indiferente para o desenvolvimento da parte aérea das mudas de goiabeira, não afetando as características avaliadas. Nas raízes, os efeitos relacionados a esse fator foram discretos, verificados apenas nos tratamentos em que o $P$ foi distribuído em todo o volume de solo do vaso (Tabela 2). Nestes, a aplicação de $P$ nos dois vasos ( $100 \%$ das raízes) permitiu maior acúmulo do nutriente e produção de matéria seca nas raízes das mudas, comparado à adição em um vaso. Isso é explicado pelo aumento considerável da quantidade de raízes que passaram a receber o estímulo ao crescimento ocasionado pelo P-externo. A fração do sistema radicular estimulada passou de 50\% (P em 1 vaso) para 100\% (P em 2 vasos).

TABELA2 - Efeito do modo de aplicação do fertilizante fosfatado em relação ao solo (distribuído em todo o solo do vaso e localizado a 1/3 de profundidade no vaso) dentro do modo de aplicação do fertilizante fosfatado em relação às raízes (em 2 vasos e em 1 vaso), e vice-versa, na concentração de fósforo do solo e no desenvolvimento de mudas de goiabeira 'Paluma', aos 100 dias após o transplantio e a adubação fosfatada.

\begin{tabular}{|c|c|c|c|c|c|c|}
\hline \multirow{4}{*}{$\begin{array}{l}\text { Modo de Aplicaçãoo } \\
\text { de P em } \\
\text { relação ao soloo }\end{array}$} & \multirow{2}{*}{\multicolumn{2}{|c|}{$\begin{array}{c}\text { Matéria Seca } \\
\text { Raízes } \\
\end{array}$}} & \multicolumn{4}{|c|}{ P acumulado } \\
\hline & & & \multicolumn{2}{|c|}{ Raízes } & \multicolumn{2}{|c|}{ Parte Aérea } \\
\hline & \multicolumn{6}{|c|}{ Modo de Aplicação de $\mathrm{P}$ em relação às Raízes } \\
\hline & Distribuído & Localizado & Distribuído & Localizado & Distribuído & Localizado \\
\hline & \multicolumn{2}{|c|}{ g por planta } & \multicolumn{4}{|c|}{ - } \\
\hline 2 vasos & $5,58 \mathrm{Aa}$ & $4,71 \mathrm{Ba}$ & $5,94 \mathrm{Aa}$ & $5,11 \mathrm{Ba}$ & $28,82 \mathrm{Ba}$ & $34,43 \mathrm{Aa}$ \\
\hline 1 vaso & $4,91 \mathrm{Ab}$ & $5,15 \mathrm{Aa}$ & $4,47 \mathrm{Bb}$ & $5,33 \mathrm{Aa}$ & $31,07 \mathrm{Aa}$ & $32,00 \mathrm{Aa}$ \\
\hline
\end{tabular}

Médias seguidas da mesma letra, maiúsculas nas linhas e minúsculas nas colunas, não diferem significativamente entre si, pelo teste de Tukey, a $5 \%$ de probabilidade.

Com a aplicação localizada de $\mathrm{P}$ a $1 / 3$ de profundidade, a fração do sistema radicular estimulada pelo P-externo não foi mensurada, mas deve variar de aproximadamente $5 \%$ (P em 1 vaso) para cerca de $10 \%(\mathrm{P}$ em 2 vasos) das raízes das plantas, o que, pelos resultados obtidos, não foi suficiente para afetar o desenvolvimento radicular total.

Esses resultados indicam que a mobilidade interna do fósforo em goiabeira é satisfatória, e que o adequado suprimento desse nutriente e bom crescimento das plantas independem da fração do sistema 
radicular em contato com o "P-disponível" do solo. Comportamento semelhante foi observado por Machado et al. (1983b) para a soja. Ao contrário, para o milho, é necessário que o maior volume de raízes esteja em contato com o $\mathrm{P}$ do solo para obter-se suprimento satisfatório e boa produção (Anghinoni \& Barber, 1980; Novais et al., 1985; Vasconcelos et al., 1986; Klepker \& Anghinoni, 1995).

Como já comentado, a adubação fosfatada afetou positivamente o desenvolvimento das mudas de goiabeira formadas em solo deficiente em P. De modo geral, o incremento nas doses de fósforo promoveu a elevação do conteúdo de $\mathrm{P}$ e da produção de matéria seca pelas raízes e parte aérea das mudas (Figuras 2 e 3 ), bem como induziu maior comprimento total de ramos, maior número de folhas e maior área foliar total por planta (Figuras 4 e 5). Todos os ajustes obtidos foram de ordem quadrática, apresentando um ponto de máximo e redução do efeito benéfico da adubação à medida que o valor da dose se aproximou de 280 $\mathrm{mg} \mathrm{dm}{ }^{-3}$, indicando eventual efeito depressivo. Contudo, o incremento de 70 para $280 \mathrm{mg}$ de $\mathrm{P} \mathrm{dm}^{-3}$ de solo afetou diferentemente as características biológicas avaliadas. Nas raízes, a partir de $70 \mathrm{mg} \mathrm{de} \mathrm{P} \mathrm{dm}^{-3}$, não houve alteração no conteúdo de $\mathrm{P}$ e massa seca produzida (Figura 2), não obstante a sensível elevação desses valores na parte aérea das mudas (Figura 3).

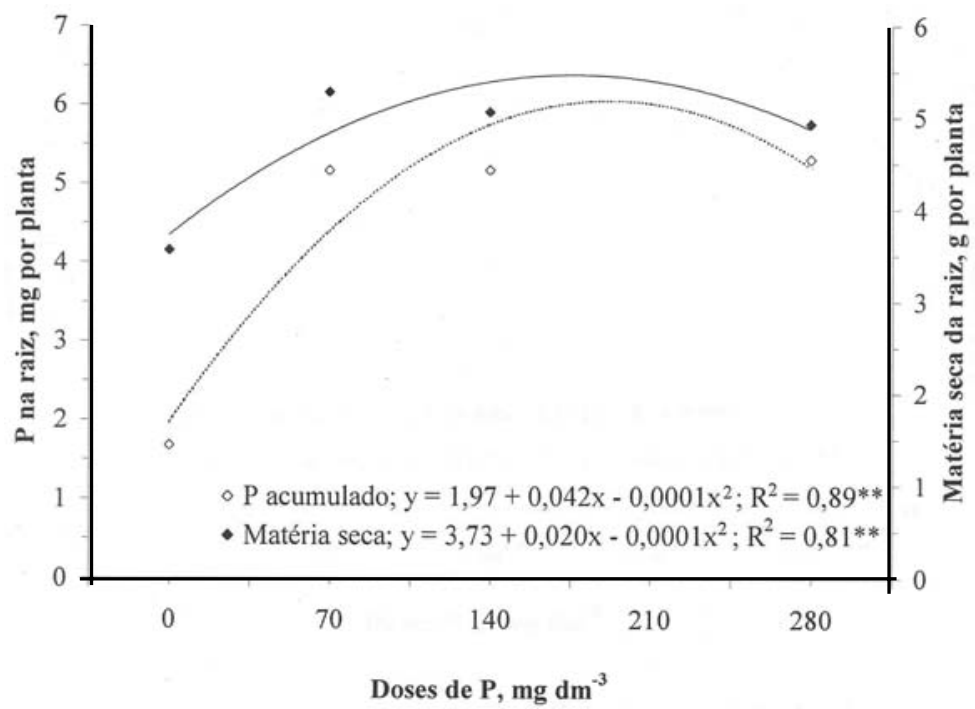

FIGURA 2- Efeito de doses de fósforo sobre o acúmulo de $\mathrm{P}$ e produção de matéria seca da raiz de mudas de goiabeira, aos 100 dias após o transplantio.

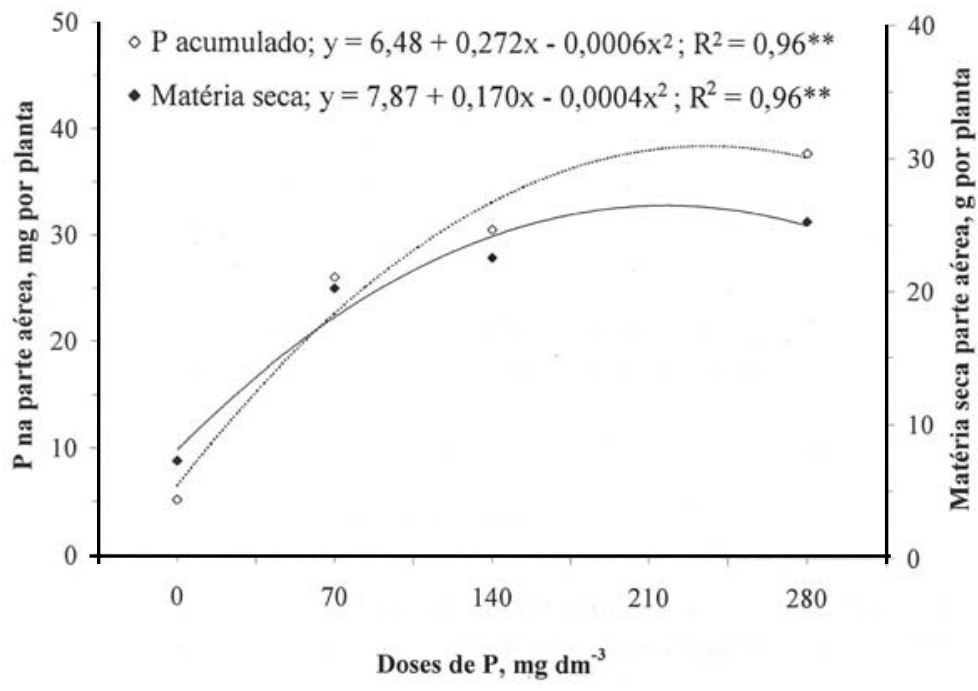

FIGURA 3- Efeito de doses de fósforo sobre o acúmulo de P e produção de matéria seca da parte aérea de mudas de goiabeira, aos 100 dias após o transplantio.

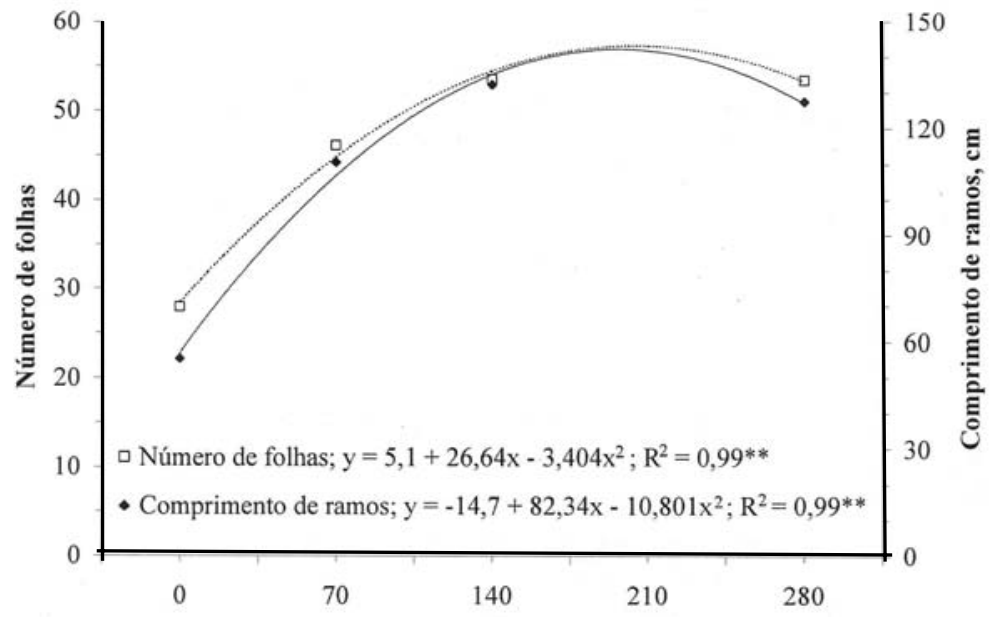

Doses de $\mathrm{P}, \mathrm{mg} \mathrm{dm}^{-3}$

FIGURA 4- Efeito de doses de fósforo no número de folhas e comprimento de ramos de mudas de goiabeira, aos 100 dias após o transplantio.

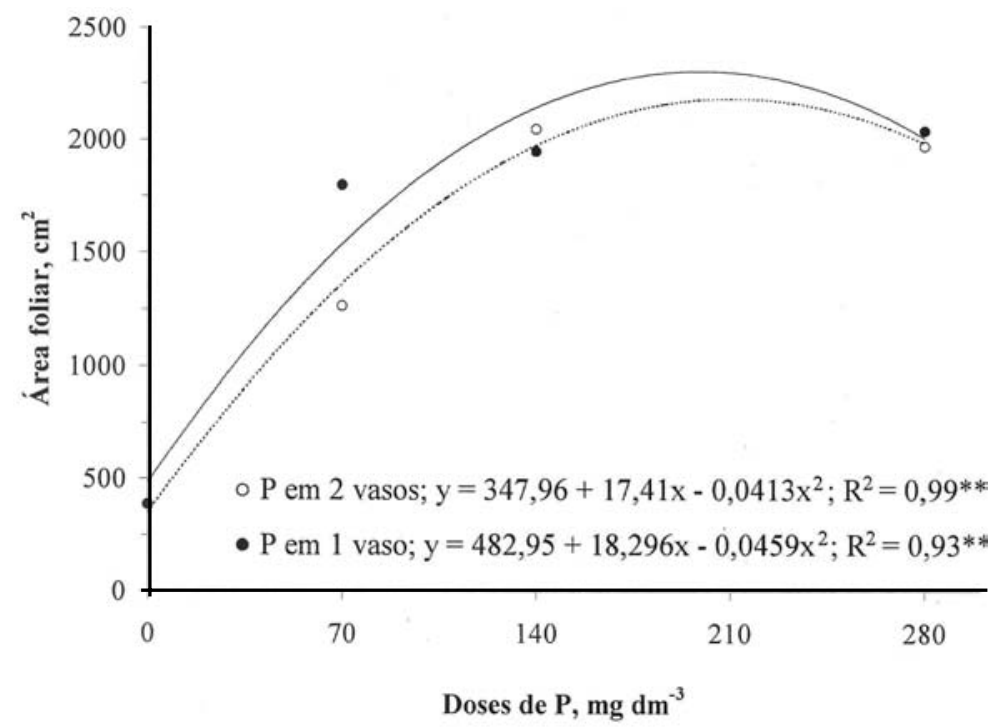

FIGURA 5- Desdobramento do efeito de doses de fósforo sobre a área foliar, dentro de formas de aplicação do adubo com relação às raízes de mudas de goiabeira, aos 100 dias após o transplantio.

A adubação fosfatada que proporcionou a máxima produção de matéria seca da parte aérea $(25,93 \mathrm{~g})$ e das raízes $(5,47 \mathrm{~g})$ das plantas,

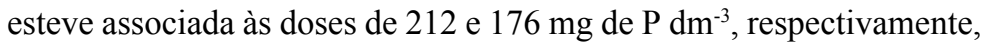
e noventa por cento das máximas produções foram relacionadas às doses de 132 e $77 \mathrm{mg}$ de $\mathrm{P} \mathrm{dm}^{-3}$ de solo, respectivamente. Com respeito às demais características da parte aérea avaliadas, noventa por cento do máximo "número de folhas", "comprimento total de ramos" e "área foliar total" por planta estiveram relacionados às doses de 113; 117 e cerca de $133 \mathrm{mg}$ de $\mathrm{P} \mathrm{dm}^{-3}$, respectivamente.

Nota-se que doses entre 110 e $135 \mathrm{mg}$ de $\mathrm{P} \mathrm{dm}{ }^{-3}$ de solo foram suficientes para a obtenção de bom desenvolvimento da parte aérea das mudas, e doses próximas de $70 \mathrm{mg} \mathrm{dm}^{-3}$ bastaram para o máximo crescimento do sistema radicular. Tais valores estão próximos da dose considerada adequada por Natale et al. (2000) para o desenvolvimento de mudas de goiabeira ( $\left.100 \mathrm{mg} \mathrm{dm}^{-3}\right)$. Outrossim, estão bem abaixo dos 200 $\mathrm{mg} \mathrm{dm}^{-3}$ recomendados por Malavolta (1980) para ensaios em vasos em geral.

Aparentemente, a eficiência na absorção e aproveitamento do fósforo do solo pela goiabeira reflete sua adaptação a solos de baixa fertilidade, naturais da sua região de origem (tropical), que em parte pode estar relacionada com uma bem-sucedida associação simbiótica 
com fungos micorrízicos arbusculares, relatada por vários autores (Chacón \& Cuenca, 1998; Samarão \& Martins, 1999).

O efeito depressivo ocorrido com o uso das maiores doses do adubo fosfatado deve-se, possivelmente, à deficiência de $\mathrm{Zn}$ induzida pelo fósforo, apesar da aplicação de zinco no plantio das mudas. Safaya (1976) relatou que o P pode inibir a absorção de Zn pela redução da translocação do micronutriente através da endoderme e epiderme da raiz. Lambert et al. (1979), por sua vez, afirmaram que doses maiores de $\mathrm{P}$ podem inibir a ação das micorrizas, prejudicando a absorção do $\mathrm{Zn}$. Entretanto, os efeitos da interação $\mathrm{P}$ x Zn na absorção desses nutrientes pelas plantas ainda não estão bem explicados.

Desdobrando-se as interações entre doses e formas de aplicação de fósforo para acúmulo de $\mathrm{P}$ e massa seca de raiz e parte aérea, verifica-se comportamento semelhante ao já comentado para os efeitos principais (Figuras 2, 3, 6 e 7). Entretanto, observa-se que, nos tratamentos em que $o$ adubo foi aplicado de forma mais localizada, a $1 / 3$ de profundidade e/ou em um só vaso, o efeito depressivo da maior dose de $\mathrm{P}$ nas características estudadas foi menos expressivo, provavelmente porque parte do sistema radicular estava crescendo em locais livres de $\mathrm{P}$, onde a absorção de $\mathrm{Zn}$ possivelmente não tenha sido afetada.

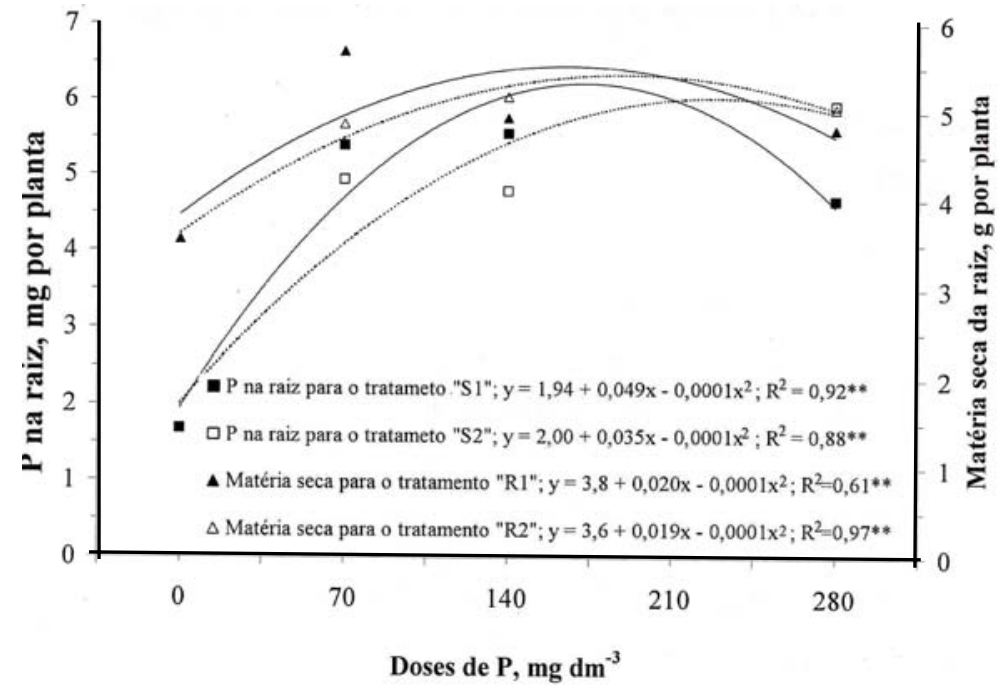

FIGURA 6- Desdobramento do efeito de doses de fósforo sobre o acúmulo de $\mathrm{P}$, dentro de formas de aplicação do adubo com relação ao solo, e sobre a produção de matéria seca da raiz, dentro de formas de aplicação com relação às raízes de mudas de goiabeira, aos 100 dias após o transplantio.

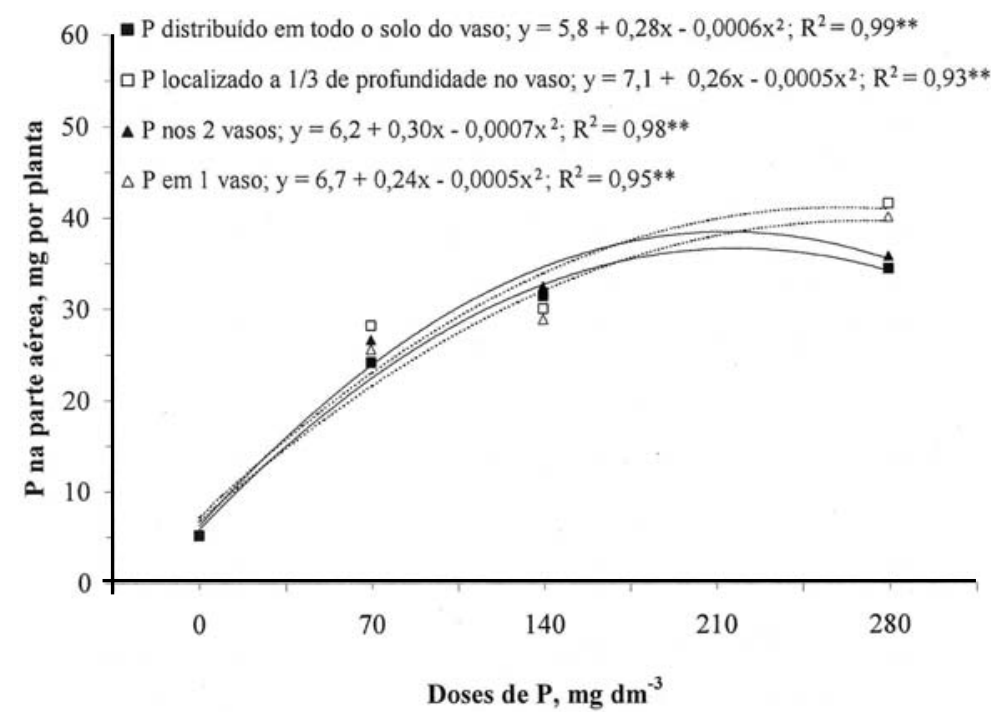

FIGURA 7- Desdobramento do efeito de doses de fósforo sobre o acúmulo de P na parte aérea, dentro de formas de aplicação do adubo com relação ao solo e às raízes de mudas de goiabeira, aos 100 dias após o transplantio.

\section{CONCLUSÕES}

1) As mudas de goiabeira responderam positivamente à adubação fosfatada, sendo a dose em torno $100 \mathrm{mg} \mathrm{de} \mathrm{P} \mathrm{dm}^{-3}$ de solo suficiente para o bom desenvolvimento das plantas.

2) Doses acima de $200 \mathrm{mg}$ de $\mathrm{P} \mathrm{dm} \mathrm{dm}^{-3}$ promoveram redução do desenvolvimento das mudas de goiabeira.

3) A aplicação de fósforo à metade ou a todo o sistema radicular da goiabeira não afetou o suprimento desse nutriente às mudas e tampouco o seu desenvolvimento em substrato deficiente em fósforo.

4) A aplicação do adubo fosfatado, distribuído em todo o volume de solo disponível no vaso, proporcionou maior desenvolvimento do sistema radicular e menor da parte aérea das mudas de goiabeira, comparado à aplicação localizada do adubo a 1/3 de profundidade.

\section{AGRADECIMENTOS}

Aos produtores José Mauro da Silva e João Mateus da Silva, pela disponibilização das mudas de goiabeira e do espaço físico, bem como pelo apoio na condução do experimento.

\section{REFERÊNCIAS BIBLIOGRÁFICAS}

AGRIANUAL: anuário da agricultura brasileira. São Paulo: FNP Consultoria e Comércio, 2002. p.367.

ANGHINONI, I. Uso de fósforo pelo milho afetado pela fração de solo fertilizada com fosfato solúvel, Revista Brasileira de Ciência do Solo, Campinas, v.16, n.2, p.349-353, 1992.

ANGHINONI, I.; BARBER, S.A. Phosphorus influx and growth characteristics of corn roots as influenced by phosphorus supply. Agronomy Journal, Madison, v.72, p.685-688, 1980.

ANUÁRIO IEA 2000. Série Informações Estatísticas da Agricultura. São Paulo, 2001, v.12, n.1, p.19.

CHACÓN, A.M.; CUENCA, G. Efecto de las micorrizas arbusculares y de la fertilización con fósforo, sobre el crecimiento de la guayaba en condiciones de vivero. Agronomía Tropical, Maracay, v.48, n.4, p.425440, 1998.

DEDECEK, R.A.; PEREIRA, J.; IKE, M.; IWATA, F. Efeito de profundidade de aração inicial, modos de adubação corretiva e sistemas de preparo do solo na produção de soja em solos de cerrado. Revista Brasileira de Ciência do Solo, Campinas, v.10, n.1, p.173-180, 1986.

KLEPKER, D.; ANGHINONI, I. Crescimento radicular e aéreo do milho em vasos em função do nível de fósforo e da localização do adubo fosfatado. Revista Brasileira de Ciência do Solo, Viçosa, v.19, p.403408, 1995.

LAMBERT, D.H.; BAKER, D.E.; COLE Jr., H. The role of mycorrhizae in the interactions of phosphorus with zinc, copper, and other elements. Soil Science of Society American Journal, Madison, v.43, p.976980, 1979.

MACHADO, R.P.; NOVAIS, R.F.; BORGES, A.C.; SEDIYAMA, C.S. Efeito da localização de diferentes doses de fósforo no vaso sobre o comportamento da soja. Revista Ceres, Viçosa, v.30, p.308-318, 1983a.

MACHADO, R.P.; NOVAIS, R.F.; SEDIYAMA, C.S.; BORGES, A.C. Efeito da localização de doses de fósforo, em relação ao sistema radicular, sobre o comportamento da soja, com a utilização da técnica de raízes subdivididas. Revista Ceres, Viçosa, v.30, p.295-307, 1983 b.

MALAVOLTA, E. Elementos de nutrição mineral de plantas. São Paulo: Ceres, $1980.251 \mathrm{p}$.

MARSCHNER, H. Mineral nutrition of higher plants. London: Academic Press, 1995. 674p.

MODEL, N.S.; ANGHINONI, I. Resposta do milho a modos de aplicação de adubos e técnicas de preparo do solo. Revista Brasileira de Ciência do Solo, Campinas, v.16, n.1, p.55-59, 1992.

NATALE, W.; CENTURION, J.F.; KANEGAE, F.P.; CONSOLINI, F.; ANDRIOLI, I. Efeitos da calagem e da adubação fosfatada na produ- 
ção de mudas de goiabeira. Revista de Agricultura, Piracicaba, v.75, n.2, p.247-261, 2000 .

NATALE, W.; COUTINHO, E.L.M.; BOARETTO, A.E.; PEREIRA, F.M. Goiabeira: calagem e adubação. Jaboticabal: FUNEP, 1996. 22p.

NOVAIS, R.F.; BARROS, N.F.; NEVES, J.C.L.; COUTO, C. Níveis críticos de fósforo no solo para o eucalipto. Revista Árvore, Viçosa, v.6, n.1, p.29-37, 1982.

NOVAIS, R.F.; FERREIRA, R.P; NEVES, J.C.L.N.; BARROS, N.F. Absorção de fósforo e crescimento do milho com sistema radicular parcialmente exposto a fonte de fósforo. Pesquisa Agropecuária Brasileira, Brasília, v.20, n.7, p.749-754, 1985.

NOVAIS, R.F.; SMYTH, T.J. Fósforo em solo e planta em condições tropicais. Viçosa, UFV, DPS, 1999.399p.

PICHETH, J.A.T.F. Viveiros florestais. Londrina: 1987. 29p. (Circular, 52).

PRADO, R.M.; FERNANDES, F.M.; ROQUE, C.G. Resposta da cultura do milho a modos de aplicação e doses de fósforo, em adubação de manutenção. Revista Brasileira de Ciência do Solo, Viçosa, v.25, n.1, p.85-92, 2001.

RAIJ, B. van; QUAGGIO, J.A.; CANTARELLA, H.; FERREIRA, M.E.; LOPES, A.S.; BATAGLIA, O.C. Análise química do solo para fins de fertilidade. Campinas: Fundação Cargill, 1987. 170p.

ROBERTSON, J.A.; KANG, B.T; RAMIREZ-PAZ, F.; WERKHOVEN, C.H.E.; OHLROGGE, A.J. Principles of nutrient uptake from fertilizer bands. VII. $\mathrm{P}^{32}$ uptake by brace roots of maize and its distribution within the leaves. Agronomy Journal, Madison, v.58, p.293-296,1966.
RÖMER, W.; SCHILLING, G. Phosphorus requirements of the wheat plant in various stages of its life cycle. Plant and Soil, Dordrecht, v.91, p.221-229, 1986.

SAFAYA, N.M. Phosphorus-zinc interaction in relation to absorption rates of phosphorus, zinc, copper, manganese, and iron in corn. Soil Science of Society American Journal, Madison, v.40, p.719-722, 1976.

SALVADOR, J.O.; MOREIRA, A.; MALAVOLTA, E. Nutrição mineral, adubação e irrigação. In: MANICA, I. (Ed.). Fruticultura tropical. 6. Goiaba. Porto Alegre: Cinco Continentes, 2000. p.154.

SAMARÃO, S.S.; MARTINS, M.A. Influência de fungos micorrízicos arbusculares, associada à aplicação de rutina, no crescimento de mudas de goiabeira (Psidium guajava L.). Revista Brasileira de Fruticultura, Jaboticabal, v.21, n.2, p.196-199, 1999.

SANTOS, P.R.; QUAGGIO, J.A. Goiaba. In: RAIJ, B. van; CANTARELLA, H.; QUAGGIO, J.A.; FURLANI, A.M.C.(Ed.) Recomendação de adubação e calagem para o estado de São Paulo. Campinas: Instituto Agronômico de Campinas, 1996. p.143.

SILVA, D.J.;ALVARENGA, R.C.; ALVAREZ, V.H.; SOARES, P.C. Localização de fósforo e de cálcio no solo e seus efeitos sobre o desenvolvimento inicial do milho. Revista Brasileira de Ciência do Solo, Campinas, v.17, n.2, p.203-209, 1993.

VASCONCELOS, C.A.; SANTOS, H.L.; FRANÇA, G.E.; BAHIAFILHO, A.F.C.; PITTA, G.V.E. Níveis, métodos de aplicação e fontes de fosfatos na produção de milho. Pesquisa Agropecuária Brasileira, Brasília, v.21, p.245-254, 1986. 